\title{
Neutronic design of MYRRHA reactor hall shielding
}

\author{
Yurdunaz Celik ${ }^{1, *}$, Alexey Stankovskiy ${ }^{1}$, and Gert Van den Eynde ${ }^{1}$ \\ ${ }^{1} \mathrm{SCK} \cdot \mathrm{CEN}$, Institute for Advanced Nuclear Systems, Boeretang 200, B-2400 Mol, Belgium
}

\begin{abstract}
The lateral shielding of a $600 \mathrm{MeV}$ proton linear accelerator beam line in the MYRRHA reactor hall has been assessed using neutronic calculations by the MCNPX code complemented with analytical predictions. Continuous beam losses were considered to define the required shielding thickness that meets the requirements for the dose rate limits. Required shielding thicknesses were investigated from the viewpoint of accidental full beam loss as well as beam loss on collimator. The results confirm that the required shielding thicknesses are highly sensitive to the spatial shape of the beam and strongly divergent beam losses. Therefore shielding barrier should be designed according to the more conservative assumptions.
\end{abstract}

\section{Introduction}

The Monte Carlo simulation technique is commonly used in radiation shielding analysis. It is based on tracking each individual particle and is considered a very reliable method. However, calculations of huge shields are computationally expensive and require special methods, such as a variance reduction, to obtain statistically reliable results. The limitations of available computing resources often restrict the use of Monte Carlo methods for thick shielding barriers. In this case the results obtained for moderate shield thicknesses can be propagated to thicker shields using analytical models.

This paper deals with the design of lateral shielding of MYRRHA reactor hall. Multi-purpose hYbrid Research Reactor for High-tech Applications (MYRRHA) is an accelerator-driven system (ADS) being designed at $\mathrm{SCK} \cdot \mathrm{CEN}$ in Belgium $[1,2]$. The 600 $\mathrm{MeV}, 4 \mathrm{~mA}$ proton beam from a high-power continuous wave superconducting linear accelerator penetrates to the reactor from the top to drive the subcritical core. The bending magnet diverting the beam into vertical direction is located above the ceiling of $35 \mathrm{~m}$-high reactor hall. The beam travelling from bending magnet through the reactor hall could experience certain proton losses on the beam focusing equipment such as collimators.

To evaluate the shielding barrier, both continuous and accidental beam losses have been considered.

Various spatial profiles of the proton beam entering the reactor hall have been studied to define the specific requirements for the reactor hall shielding. The required minimum shielding thickness was determined according to the dose rate limits for the public and controlled area behind the shielding. The sensitivity of the required shielding thickness to the proton source distributions and analytical model is discussed as well.
The induced radioactivity and residual doses in reactor hall have also been calculated in order to better evaluate the required shield thicknesses.

\section{Geometry and Method}

The structure of a $35 \mathrm{~m}$ high vertical part of the beam line below the last bending magnet and penetrating the reactor hall is shown in Fig. 1. The inner diameter of 13.75-mm thick ferritic-martensitic T91 stainless steel (SS) beam tube is $84.3 \mathrm{~mm}$. The distance between the beam tube and inner wall of concrete biological shieldingis $8 \mathrm{~m}$. This volume is filled with air in the model. A $3 \mathrm{~m}$ thick standard concrete cylinder models the biological shielding. The components of the reactor cover (stainless steel plates enclosing borated water with penetrations for primary heat exchanger, primary pumps and in vessel fuel handling machine) were also included in the geometry in order to simulate their influence on the dose distribution.

After the bending magnet the divergent beam must be collimated by the collimator for an optimal beam profile. This will protect the beam line and reactor cover components in the reactor hall from protons deviated from their prescribed trajectory. Therefore, the computational model contains the collimator $1 \mathrm{~m}$ below the reactor hall ceiling.

Since different beam loss scenarios may lead to completely different dose distributions, the effects of proton beam spatial shapes on a required shielding thickness during a routine accelerator operation have been investigated.

A reference profile models the Gaussian beam $(\sigma=9$ $\mathrm{mm}$ ) swept around the central axis with the sweeping radius being $21.5 \mathrm{~mm} \mathrm{[3].} \mathrm{To} \mathrm{simulate} \mathrm{the} \mathrm{beam} \mathrm{loss,} \mathrm{the}$ source was diverted by $0.07^{\circ}$ at the top of $35 \mathrm{~m}$-high vertical beam line. The beam profile is shown in Fig. 2.

\footnotetext{
*Corresponding author: ycelik@sckcen.be
} 


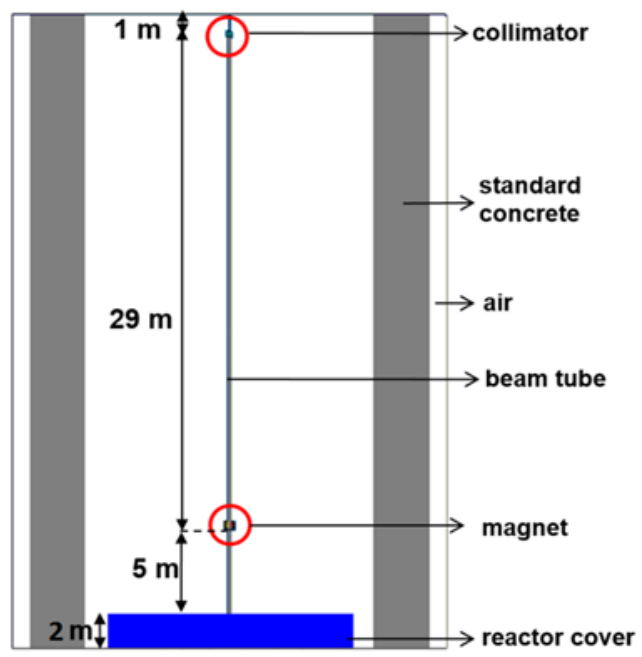

Figure 1. Vertical beam line geometry.

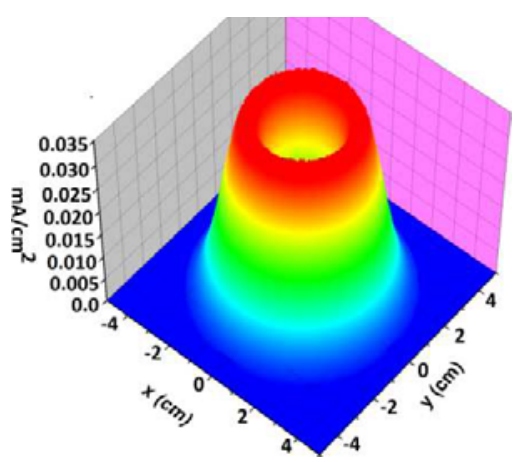

Figure 2. Profile of the sweeping proton beam at the top of the vertical beam line (reactor hall ceiling).

Another beam profile, a virtual one, is used to assess the dose rates in the situation when all the protons hit the beam tube close to the reactor cover. The source protons were linearly distributed in a $1 \mathrm{~m}$ long segment of the central axis and directed downwards to hit the beam tube at the last meter above the reactor cover.

To account beam losses on the collimator in a most conservative way, another virtual beam profile has been developed, representing a concial shape where protons launched from a point source above the hall ceiling with a divergence of $7.41^{\circ}$ from the original beam direction hit the collimator.

The attenuation doses in the shielding were fitted by double-exponential functions [4-6], which assume a uniform beam loss along a linear proton source (henceforth denoted as "function 1") and a localized point source (henceforth denoted as "function 2"), see Eq. 1 and Eq.2, respectively.

$$
\begin{aligned}
& H(d)=\frac{H_{1}}{r} \exp \left(-\frac{d}{0.94 \lambda_{1}}\right)+\frac{H_{2}}{r} \exp \left(-\frac{d}{0.94 \lambda_{2}}\right) \\
& H(d)=\frac{H_{1}}{\mathrm{r}^{2}} \exp \left(-\frac{d}{\lambda_{1}}\right)+\frac{H_{2}}{\mathrm{r}^{2}} \exp \left(-\frac{d}{\lambda_{2}}\right)
\end{aligned}
$$

where $\mathrm{H}(\mathrm{d})$ is the dose equivalent at depth $\mathrm{d}$ in shield, $\left(\mathrm{H}_{1}, \lambda_{1}\right)$ and $\left(\mathrm{H}_{2}, \lambda_{2}\right)$ are source terms and the attenuation lengths of the small thickness and large thickness of shield, respectively, $d$ is the thickness of the shield and $\mathrm{r}=\mathrm{a}+\mathrm{d}$, where $\mathrm{a}$ is the distance from the radiation source to the inner wall of the shield.

Shielding calculations have been performed with the general purpose radiation transport code MCNPX2.7.0 [7]. The ambient equivalent doses have been calculated in MCNPX by collapsing the particle fluxes with energy-dependent dose conversion factors. Flux-toambient dose conversion factors were taken from the ICRP report 74 [8] for neutrons up to $200 \mathrm{MeV}$. For neutrons of higher energies as well as for protons and photons of all energies the functions from Ref. [9] have been used. Collimator activation and residual dose calculations have been carried out with the ALEPH2 depletion code developed at SCK-CEN [10] to determine the final disposal options and to assess the residual dose rate, which the workers or the equipment will be subject to during occasional maintenance and/or repair of collimator.

According to the IAEA recommendations [11] the dose equivalent rate limit for normal operation is 0.1 $\mu \mathrm{Sv} / \mathrm{h}$ for public areas and $10 \mu \mathrm{Sv} / \mathrm{h}$ for controlled areas. When the operating time is assumed to be 270 day per year, i.e., $6480 \mathrm{~h} \mathrm{y}^{-1}$, these values will ensure that the annual dose limits of $1 \mathrm{mSv}$ for the public and $20 \mathrm{mSv}$ for workers will not be exceeded.

\section{Main results}

\subsection{Normal operation losses on beam tube}

For normal operation conditions we assume a loss of 10 $\mathrm{W}$ along every meter of the vertical beam line [12], with

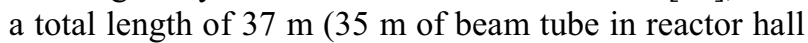
and $2 \mathrm{~m}$ in the reactor cover). This value corresponds to beam losses of $3.84 \times 10^{12}$ protons per meter and per second ( $37 \mathrm{~m} \times 1.04 \times 10^{11} \mathrm{p} / \mathrm{s}$ per meter).

The spatial distributions of the dose rates in the whole geometry for two proton source distributions are shown in Fig. 3.

The dose rates in the air around the beam tube rise up to $10^{7} \mu \mathrm{Sv} / \mathrm{h}$ in case of the reference Gaussian beam profile (a). Because of the spatial distribution of the proton flux in case of linear source distribution, the ambient equivalent dose is concentrated in the region around the last meter of the beam line (b). Dose rates decrease by almost two orders of magnitude in the reactor hall air if the linear proton source profile is considered. On the other hand, using linear source one gets the dose values behind the biological shielding lower than the control area dose limit $(10 \mu \mathrm{Sv} / \mathrm{h})$, while in case of Gaussian source the dose values are around $200 \mu \mathrm{Sv} / \mathrm{h}$. Provided that access to this area is allowed only when the accelerator is not operational, the dose rate in these areas does not represent any danger. 


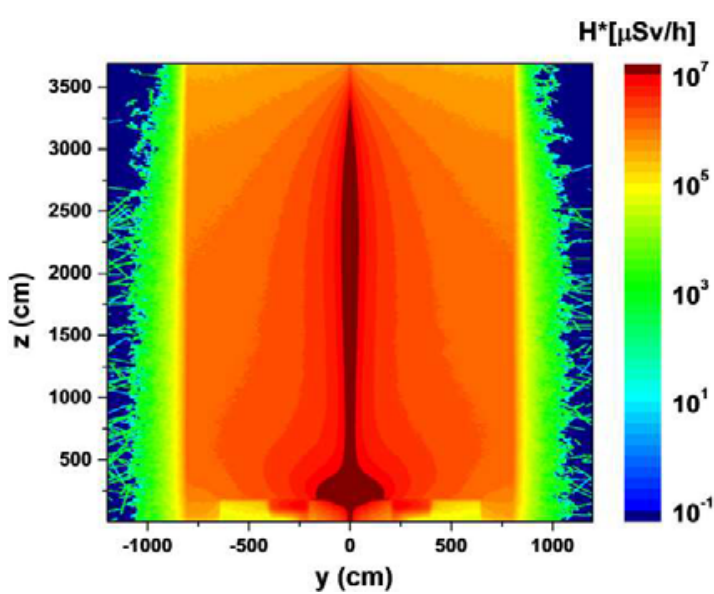

a)

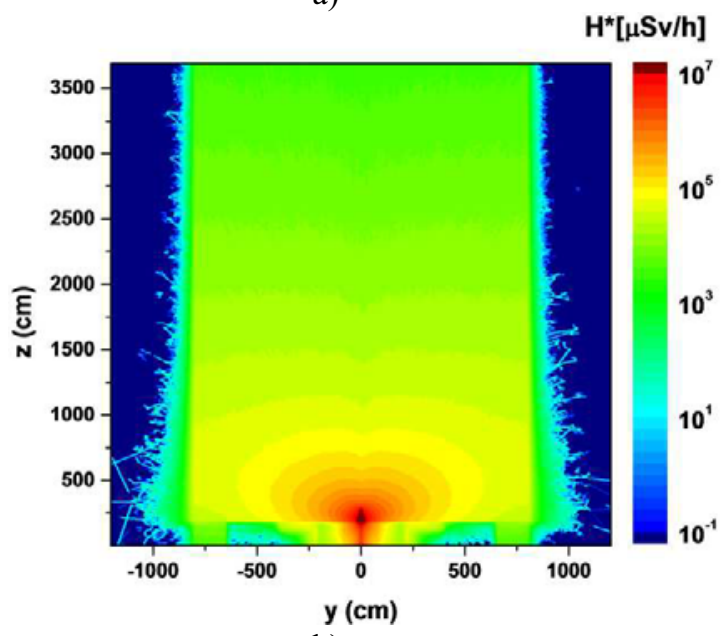

b)

Figure 3. Spatial distribution of the dose rate for a) reference Gaussian source and b) line source.

Fig. 4 (a) displays the ambient equivalent doses calculated as a function of shield thickness. This plot allows to determine the required thickness according to the classification of the area behind the shielding. The calculated doses were fitted and extrapolated for larger depths by dose function 1 . The first term of the function 1 describes the attenuation of dose below $0.45 \mathrm{~cm}$. The rest of the data was extrapolated for second term of function 1. This value sreflects the equilibrium state when the neutron spectrum shape does not change with the shield depth and the neutron attenuation is purely exponential.

Clearly, there is a significant difference in the required shield thicknesses to reach the safety limits for the public and controlled areas. The dose curves are highly sensitive to the primary proton source distribution. In case of a Gaussian source, biological shieldings with thicknesses of about $4.07 \mathrm{~m}$ and $5.95 \mathrm{~m}$ are needed to remain within the controlled area and public area dose limits, respectively, while for a linear source distribution thicknesses of only $2.35 \mathrm{~m}$ and 4.10 $\mathrm{m}$ are sufficient. This huge difference reflects the differences in model assumptions for the beam losses: the Gaussian beam profile provides uniformly distributed losses along the height of the reactor hall, while the linear beam profile results in losses concentrated in the last meter of the beam tube above the reactor cover.
The neutron attenuation profiles obtained using the line source distribution were also fitted by function 2 assuming a localized radiation point source. A comparison between the raw data and fit of the neutron dose rate attenuation for point and linear source equations is shown in Fig. 4 (b). The usual approach that can be found in the literature [13-15] is either to use a line source in calculations and then fit the calculated values with equation (1) or to use a point source in calculations and fit the calculated values with equation (2). We demonstrated here that the data points obtained using linear source distribution are in very good agreement with both functions 1 and 2 up to $4 \mathrm{~m}$ of shield thickness. Above this thickness the two fits begin to deviate. The fit by function 1 guarantees a conservative estimation of the required thickness. This comparison was also performed for the Gaussian source and these two functions provide a similar required shielding thicknesses through the whole fit line.

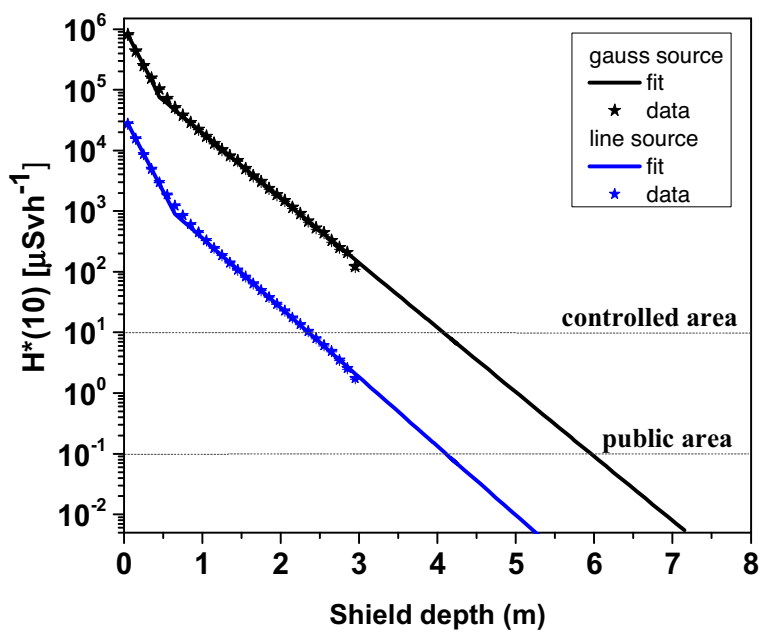

(a)

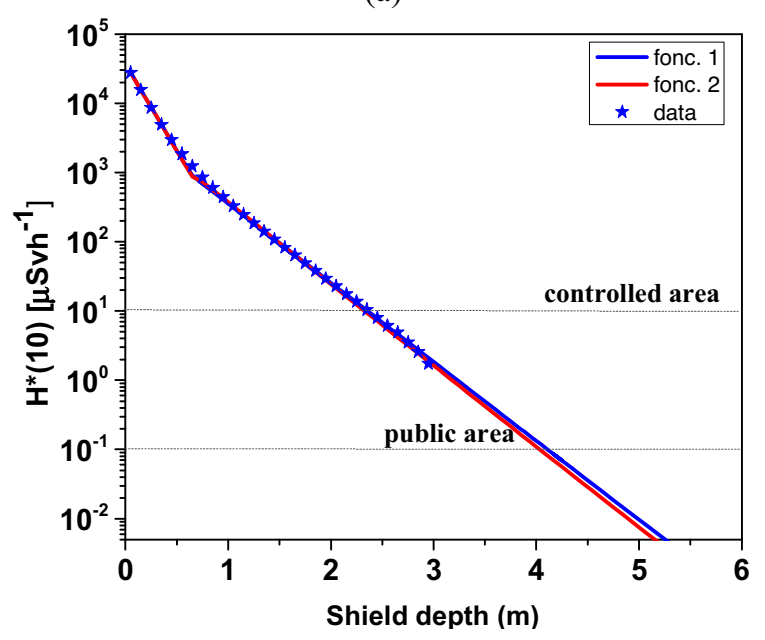

(b)

Figure 4. a) Neutron dose rate attenuation curves in standard concrete used as biological shielding for Gaussian and linear proton source distributions. b) Comparison between the fits by functions 1 and 2 to the data obtained with the line source distribution. The dose rate limits for controlled and public areas are indicated by the dashed lines. 


\subsection{Normal operation losses on collimator}

The collimator is of particular concern due to exposure by the strongly divergent beam from the bending magnet. It was assumed that the collimator absorbs $1 \%$ of the total proton current $(4 \mathrm{~mA})$. However, it is an important source of secondary particles, which can cause induced radioactivity and prompt doses. Therefore, to evaluate the shield thickness in the presence of collimator in the reactor hall the doses must not be underestimated.

A simple cylinder was used to simulate the collimator geometry. The collimator height was determined by a range of $600 \mathrm{MeV}$ protons in the material. The projected range estimated with the SRIM code [16] was found to be $30 \mathrm{~cm}$ for copper. The diameter of the collimator made of copper (without the beam tube) equals to the height. The elemental composition of copper with account of impurities necessary for accurate activation and secondary doses calculations is shown in Table 1.

Table 1: Elemental composition used in [17] for MCNPX calculations. The density is $8.96 \mathrm{~g} / \mathrm{cm}^{3}$ at room temperature.

\begin{tabular}{cccccc}
\hline Element & wt. \% & Element & wt. \% & Element & wt. \% \\
\hline $\mathrm{Cu}$ & 99.9769 & $\mathrm{Ca}$ & 0.00025 & $\mathrm{Mo}$ & 0.0003 \\
\hline $\mathrm{Li}$ & 0.00005 & $\mathrm{Ti}$ & 0.0001 & $\mathrm{Ag}$ & 0.0013 \\
\hline $\mathrm{B}$ & 0.00005 & $\mathrm{~V}$ & 0.00015 & $\mathrm{Sn}$ & 0.0005 \\
\hline $\mathrm{N}$ & 0.001 & $\mathrm{Cr}$ & 0.0001 & $\mathrm{Cs}$ & 0.0001 \\
\hline $\mathrm{Na}$ & 0.0001 & $\mathrm{Mn}$ & 0.00005 & $\mathrm{Ba}$ & 0.00004 \\
\hline $\mathrm{Mg}$ & 0.00005 & $\mathrm{Fe}$ & 0.006 & $\mathrm{Eu}$ & 0.00002 \\
\hline $\mathrm{Al}$ & 0.001 & $\mathrm{Co}$ & 0.00005 & $\mathrm{Ho}$ & 0.0001 \\
\hline $\mathrm{Si}$ & 0.0001 & $\mathrm{Ni}$ & 0.0004 & $\mathrm{Hg}$ & 0.0002 \\
\hline $\mathrm{P}$ & 0.004 & $\mathrm{Zn}$ & 0.0006 & $\mathrm{~Pb}$ & 0.0008 \\
\hline $\mathrm{S}$ & 0.0015 & $\mathrm{Ga}$ & 0.0002 & $\mathrm{Bi}$ & 0.0001 \\
\hline $\mathrm{Cl}$ & 0.003 & $\mathrm{As}$ & 0.0001 & $\mathrm{Th}$ & 0.00005 \\
\hline $\mathrm{K}$ & 0.00005 & $\mathrm{Rb}$ & 0.0001 & $\mathrm{U}$ & 0.00005 \\
\hline
\end{tabular}

Fig. 5 shows the axial distributions of the energy deposited by neutrons, protons and photons. One can see that protons determine the largest part of the total heating. The proton heating density decreases with increasing depth of collimator thickness. Between depth of 23 and $25 \mathrm{~cm}$ there is a sharp decrease in proton heating since the primary protons are fully stopped by electromagnetic interactions. Residual proton heating at higher depth is due to secondary protons produced by neutrons in copper. The second largest contribution to the total heating density comes from photons. Contribution of neutrons is negligible.

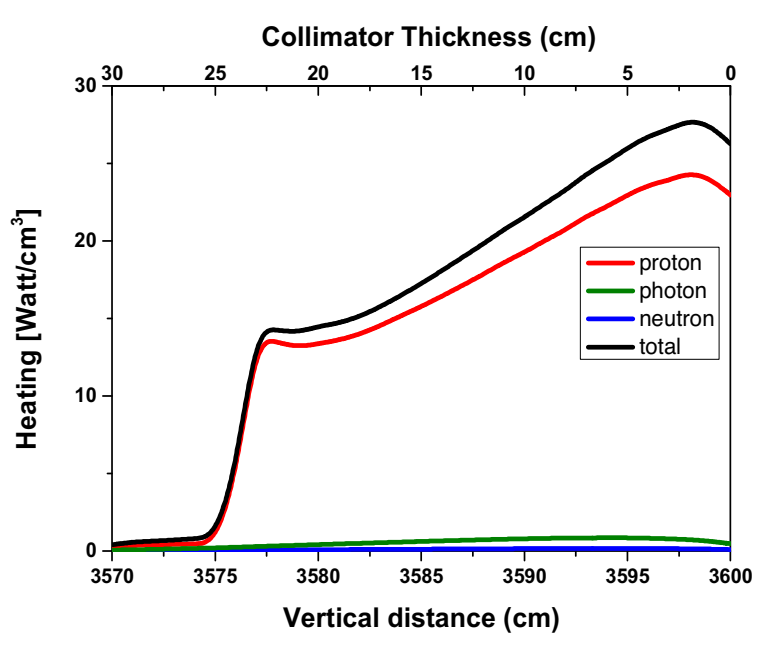

Figure 5. Energy deposition in the copper collimator.

The spatial distribution of the neutron ambient equivalent dose in the entire geometry is shown in Fig. 6. Large quantities of neutron doses, which are represented by the red colour, are produced by interactions with copper and the plot shows the doses exceed $10^{7} \mu \mathrm{Sv} / \mathrm{h}$. It is clearly seen that the collimator itself behaves as a radiation source in the reactor hall and causes higher doses complementary to ones produced during routine accelerator operation.

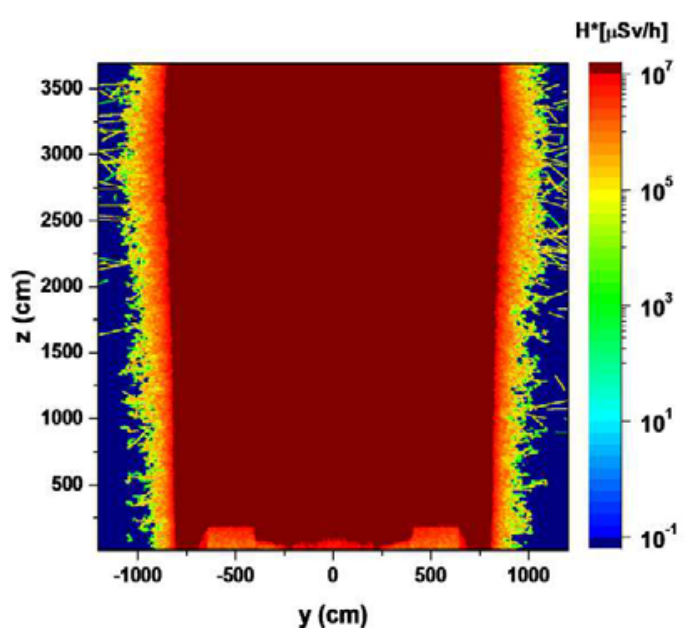

Figure 6. Dose rate spatial distributions in case of beam loss on collimator.

Detailed dose rates in the biological shielding are shown in Fig. 7. To identify the required shield thickness, dose values were fitted to function 2. According to the calculation results, the shield thicknesses determined by normal operation beam losses (see Fig. 4 (a)) do not meet dose limits due to additional doses produced by collimator. In this case, to reach the safety limits, $6.33 \mathrm{~m}$ and $8.25 \mathrm{~m}$ of shielding for the controlled and public area are needed, respectively. 


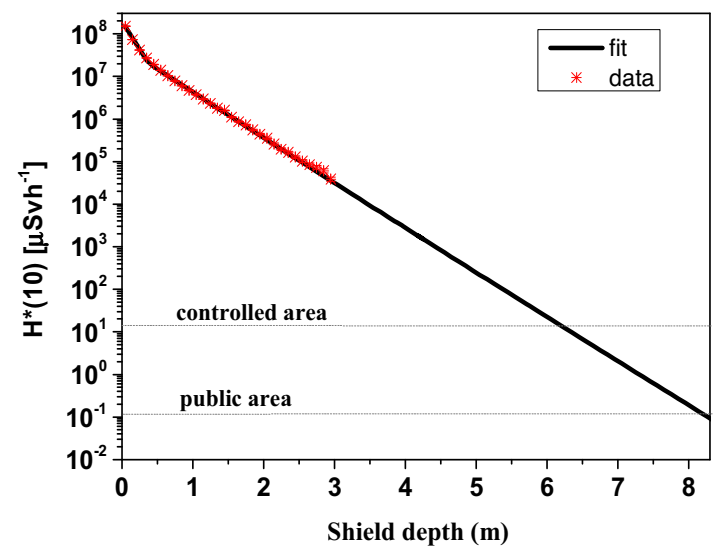

Figure 7. Neutron dose rate attenuation curve in biological shielding for beam loss on collimator.

\subsection{Accidental full beam losses}

An accidental scenario of full loss of a $4 \mathrm{~mA}$ proton beam $\left(2.5 \times 10^{16}\right.$ protons per second) was considered to define the maximum acceptable integrated dose that can be received by personnel who may be present in the area. To simulate full beam loss in this case, the primary protons have been launched from both linearly distributed source and Gaussian source. The loss from the linear source produces an instantaneous equivalent dose rate of $2.4 \times 10^{6} \mu \mathrm{Sv}^{-1}$ after a minimum of $2.24 \mathrm{~m}$ biological shielding in order to remain below the controlled area limit. When the accelerator is interrupted within $100 \mu \mathrm{s}$, the integrated dose equivalent is about $0.07 \mu \mathrm{Sv}$ for the controlled area, as is demonstrated in Figure 3. The shield thickness obtained for normal operation beam loss is thus also acceptable for the full loss if the accelerator power is cut within $100 \mu \mathrm{s}$. The integrated dose from full beam loss for the Gaussian source distribution is $0.002 \mu \mathrm{Sv}$ behind $4.07 \mathrm{~m}$ of biological shielding that is below the controlled area limit. If full beam loss is assumed on the collimator, integrated doses will be $3 \times 10^{-5} \mu \mathrm{Sv}$ for the control area behind $6.35 \mathrm{~m}$ of shield barrier.

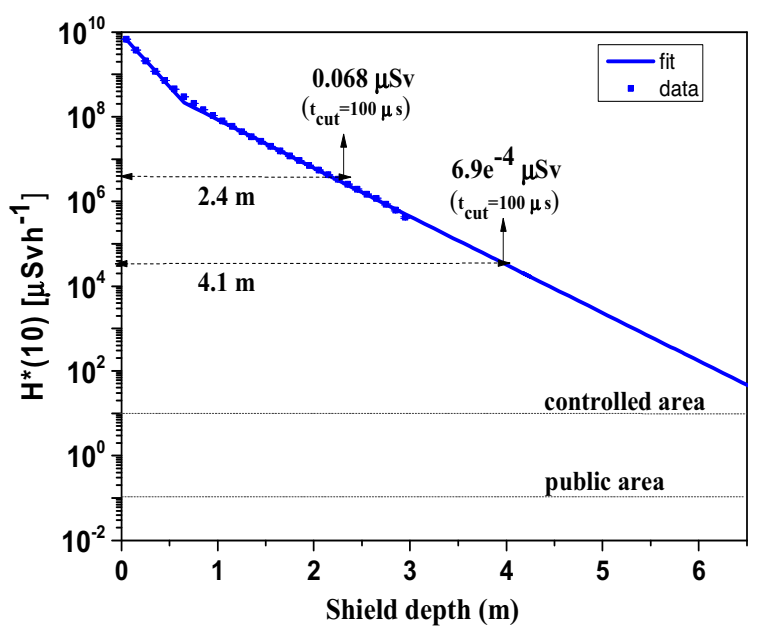

Figure 8. Nutron dose rate attenuation in the biological shielding at full beam loss.

\subsection{Activation of the Collimator}

Even if the collimator is designed to withstand the radiation, it becomes highly radioactive due to the proton beam exposure. The dominant isotopic activities in the collimator are presented as a function of time in Fig. 9 for 40 years of operation and $10^{5}$ years of cooling.

During irradiation the dominant radioisotopes produced in the copper are ${ }^{57} \mathrm{Co},{ }^{55} \mathrm{Fe}$ and ${ }^{49} \mathrm{~V}$. They both decay quickly after the end of operation due to their relatively short half-lives. ${ }^{53} \mathrm{Mn},{ }^{36} \mathrm{Cl},{ }^{41} \mathrm{Ca},{ }^{59} \mathrm{Ni}$ and ${ }^{14} \mathrm{C}$ are major contributors in the total activity until $10^{5}$ years after shut down. It is clear that copper collimator will remain highly activated long after irradiation. Therefore alternative low-activated materials such as graphite are suggested.

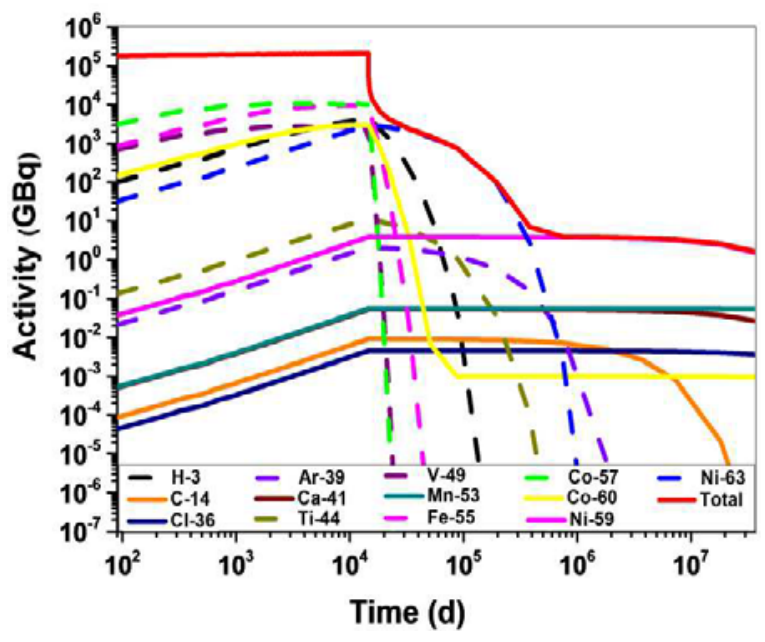

Figure 9: Time behaviour of copper collimator activity.

\subsection{Residual gamma doses}

After its operational lifetime, the collimator will be removed from the reactor hall and placed in the storage. It is important to know the dose rates in the close proximity of the collimator. Therefore, additional calculation was performed to determine residual gamma doses in the air at $1 \mathrm{~m}$ from the collimator. A separate MCNPX photon transport problem with a simple geometry including the collimator surrounded by air was has been developed. The energy spectrum of residual gamma rays emitted from the collimator at different cooling times was used as photon source distribution.

Fig. 10 shows residual gamma doses during $10^{5}$ years of cooling after 40 years of operation. There is observed a slow decrease in dose rates since copper produce significant amounts of long living isotopes such as ${ }^{59} \mathrm{Ni}$, ${ }^{53} \mathrm{Mn},{ }^{41} \mathrm{Ca}$. After 200 years of cooling dose rates reach controlled area dose limit $10 \mu \mathrm{Sv} / \mathrm{h}$. In order to reduce the radiation exposure during maintenance of the collimator, the collimator must be covered with sufficient shielding. 


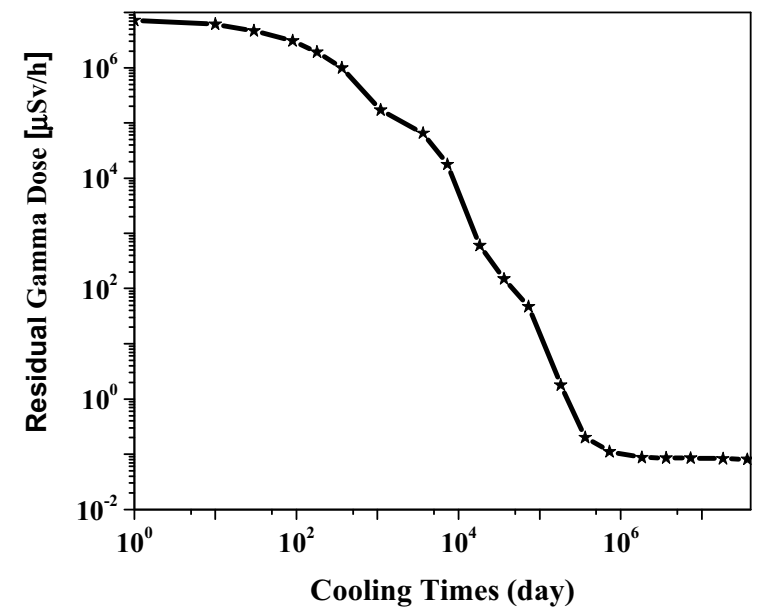

Figure 10: The residual dose rate in the air at $1 \mathrm{~m}$ distance from collimator.

\section{Conclusion}

The minimum required shielding thicknesses depend on the primary proton source spatial distributions for the fixed beam line geometry, spatial location of beam losses and their absolute values. The results demonstrate that the minimum shielding thicknesses defined for normal operation conditions meet the radiation dose limits in case of full beam loss. However, the integrated doses at full beam loss could be high, especially when the shield thicknesses are designed according to optimistic assumptions. To ensure the integrated doses at accidental conditions to be below the dose limits, the most conservative source distribution and strong divergent beam losses must be used for simulations, providing highest dose rates.

The obtained results also show that the copper collimator produces high dose levels even after shut down. From the radiation protection point of view it should be shielded also in the storage area to protect workers and equipment.

\section{References}

1. R. Fernandez, et al. MYRRHA Primary System Design Technical Description Rev.1.6, SCK·CEN/1088304 (2014)

2. E. Malambu and A. Stankovskiy, Revised core design for MYRRHA - Rev. 1.6, $\mathrm{SCK} \cdot \mathrm{CEN} / 3958903$ (2014).

3. S. Keijers et al., "Design of the MYRRHA spallation target assembly", Proc. $13^{\text {th }}$ Information Exchange Meeting on Actinide and Fission product Partitioning and Transmutation, Seoul, Korea, 23-26 September 2014.

4. S. Agosteo, T. Nakamura, M. Silari, Z. Zajacova, Attenuation curves in concrete of neutrons from 100 to $400 \mathrm{MeV}$ per nucleon $\mathrm{He} \mathrm{C}, \mathrm{Ne}, \mathrm{Ar}, \mathrm{Fe}$ and $\mathrm{Xe}$ ions on various targets, Nucl. Instr Meth .B 217, 221-336 (2004)

5. S. Agosteo, G. Fehrenbacher, M. Silari, Attenuation curves in concrete of neutrons from $1 \mathrm{GeV} / \mathrm{u} \mathrm{C}$ and
$\mathrm{U}$ ions on a Fe target for the shielding design of RIB in-flight facilities, Nucl. Instr. Meth. B 226, 231472 (2004).

6. A. H. Sullivan, A Guide to Radiation and Readioactivity Levels Near High-Energy Particle Accelerators, Nuclear technology Publishing (1992).

7. D .B. Pelowitz, et al., "MCNPX 2.7.0 Extensions", LA-UR-11-02295 (2011).

8. International Commission on Radiation Protection, "Conversion coefficients for use in radiological pro-tection against external radiation," ICRP Publication 74, Pergamon Press, Oxford (1997).

9. M. Pelliccioni, Overview of fluence-toeffective dose and fluence-to-ambient dose equivalent conversion coefficients for high energy radiation calculated using the fluka code, Radiation Protection Dosimetry 88 (2000) 279-297.

10. A. Stankovskiy, G. Van den Eynde, Sci. Thechnol. Nucl. Install, 2012;2012. 545103.

11. IAEA, Radiation Protection Programmes for the Transport of Radioactive Material, IAEA Safety Standards Series No. TS-G-1.3, Vienna (2007).

12. D. Vandeplassche, private communication, $\mathrm{SCK} \cdot \mathrm{CEN}(2014)$.

13. S. Agosteo, G. Fehrenbacher, M. Silari, Attenuation Curves in Concrete of Neutrons from $1 \mathrm{GeV} / \mathrm{u} \mathrm{C}$ and $\mathrm{U}$ Ions on a Fe target for the Shielding Design of RIB in-Flight Facilities, Nucl. Instrum. Methods B 226 (2004a) 231-472.

14. S. Agosteo, T. Nakamura, M. Silari, Z. Zajacova, Attenuation Curves in Concrete of Neutrons from 100 to $400 \mathrm{MeV}$ per Nucleon $\mathrm{He} \mathrm{C}, \mathrm{Ne}, \mathrm{Ar}, \mathrm{Fe}$ and $\mathrm{Xe}$ Ions on Various Ttargets, Nucl. Instrum. Methods B 217 (2004b) 221-336.

15. D. Ene et al., Radiation Protection Studies for ESS Superconducting Linear Accelerator, Progress in Nuclear Science and Technology 2 (2011) 382-388.

16. www.SRIM.org.

17. M.Wohlmuther, et al., Validation of Activation Calculations with MCNPX with Samples from a Copper Beam Dump, Proc. AccApp'07, Pocatello, ID AIP Press (2007), p.259. 